\title{
PENGELOLAAN KEWIRAUSAHAAN DI ERA 4G UNTUK PENINGKATAN KESEJAHTERAAN DI DESA CICALENGKA KECAMATAN PAGEDANGAN KABUPATEN TANGERANG BANTEN
}

\author{
Suwanto, Priehadi Dhasa Eka, Angga Juanda, Muhammad Gandung, \\ Prasetyo Kurniawan \\ Universitas Pamulang \\ Email: dosen1813@unpam.ac.id
}

\begin{abstract}
The purpose of doing this community service is: to find out how the opportunities of the community (Cicalengka residents, Pagedangan District) in entrepreneurship in the digital industry 4.0 era, to find out how to carry out entrepreneurial management in the digital industry 4.0 era in Cicalengka residents, Pagedangan District and to build a strong character society, independent, productive and creative and innovative in entrepreneurship. This community service is carried out to the residents of Cicalengka, Pagedangan District, whose address is at $\mathrm{Jl}$ Pagedangan, $\mathrm{kp}$ pagedangan, RT 001 RW 002, Cicalengka Village, Pagedangan District, Tangerang-Banten Regency. Conducted on Saturdays and Sundays from 5 to 6 September 2020. Mentoring is carried out in groups. Participants who took part in this service were 45 people from Cicalengka, Pagedangan District. The results obtained in this service are that every community in this case in the residents of Cicalengka, Pagedangan District has the same opportunities as other people in carrying out entrepreneurship in the $4 G$ digital industry era after receiving training and motivation and must be brave to start it. Running entrepreneurial management in the $4 G$ digital industry era can be done by anyone, anytime they don't know the place and time and who the customers are, especially those who run the business are young people (millennial).
\end{abstract}

Keywords: Management, Entrepreneurship and the $4 G$ industry.

\begin{abstract}
Abstrak
Tujuan dilakukannya pengabdian masyarakat ini adalah: untuk mengetahui bagaimana peluang masyarakat (warga Cicalengka Kecamatan Pagedangan) dalam kewirausahaan di era industry digital 4.0, untuk mengetahui bagaimana menjalankan menejemen kewirausaha pada era industry digital 4.0 di warga Cicalengka Kecamatan Pagedangan dan untuk membangun masyarakat yang berkarakter kuat, mandiri, produktif dan kreatif serta inovatif dalam berwirausaha. Pengabdian kepada masyarakat ini dilakukan pada warga Cicalengka Kecamatan Pagedangan yang beralamat di J1 Pagedangan kp pagedangan RT 001 RW 002 Desa Cicalengka kecamatan Pagedangan Kabupaten Tangerang-Banten. Dilakukan pada hari sabtu dan
\end{abstract}




\section{P-ISSN 2716-3652 E-ISSN 2723-1003 \\ DEDIKASI PKM UNPAM}

Vol. 1, No. 3, September 2020, Hal (103-108)

@Prodi Manajemen Fakultas Ekonomi Universitas Pamulang

minggu tanggal 5 sampai 6 September 2020. Pendampingan dilakukan secara kelompok. Peserta yang mengikuti pengabdian ini adalah warga Cicalengka Kecamatan Pagedangan, berjumlah 45 orang. Adapun hasil yang didapatkan di dalam pengabdian ini adalah Setiap masyarakat dalam hal ini di warga Cicalengka Kecamatan Pagedangan memiliki peluang yang sama dengan masyarakat yang lainnya dalam menjalankan kewiraussahaan di era industry digital $4 \mathrm{G}$ setelah mendapatka pelatihan dan motivasi dan harus berani untuk memulainya. Menjalankan menejemen kewirausaha pada era industry digital 4G dapat dilakukan oleh siapa saja, kapan saja tidak mengenal tempat dan waktu dan siapa pelanggannya, terlebih yang menjalankan bisnis tersebut adalah anak-anak muda (milenial).

Kata Kunci: Manejemen, Kewirausahaan dan industry 4G.

\section{A. PENDAHULUAN}

Perkembangan ilmu pengetahuan dan teknologi sekarang membuat dunia ini seakanakan sedang lari. Kita pun harus ikut berlari kalau tidak, kita akan ketinggalan. Kalimat di atas cocok dengan globalisasi dewasa ini. Globalisasi telah mempengaruhi seluruh hidup kita. Sebagai contoh, kita bias menonton pertandingan sepak bola yang diadakan di italia, spanyol dan Negara-negara lain. Arus globalisasi jelas tidak bisa dibendung. Mengapa demikian? Karena arus itu ibarat air yang mengalir deras. Oleh karena itu, globalisasi harus kita ikuti dan kita tangkap sebagai peluang. Tinggal bagaimana kita dapat memanfa'atkan globalisasi dalam hal yang positif atau tidak.

Dengan adanya kewirausahaan masyarakat dapat mempunyai kemampuan untuk menciptakan dan menyediakan produk yang bernilai tambah atau inovasi-inovasi yang baru sehingga dapat menjadikan masyarakat lebih kreatif dalam menyampaikan ide-ide dan kreasinya, mereka bisa menciptakan barang yang dirasa perlu dan penting untuk kesejahteraan masyarakat itu sendiri sehingga tidak perlu menimpor dari luar negeri. Selain itu masyarakat tidak tergantung dengan pemerintah seperti tenaga kerja negri (PNS) yang masih di gaji oleh pemerintah, bahkan seorang wirausaha akan mendatangkan omset yang akan di berikan ke negara melalui pajak. Secara tidak langsung kesejahteraan ekonomi masyarakat bisa stabil.

Sebagai manusia yang hidup di zaman yang modern seperti ini tentunya kita tidak boleh berpangku tangan atau mengandalkan orang lain saja. Kita harus bisa bersaing untuk mempertahankan hidup kita kearah yang lebih baik agar tidak ketinggalan dengan orang lain atau bangsa lain. Oleh karena itu kita dituntut untuk menjadi manusia yang mandiri dalam segala hal, terutama bagaimana kita dapat mengambil peluang-peluang yang ada di hadapan kita, terutama bagaimana kita bisa menjadi seorang wirausaha?. Ekonomi digital di Indonesia memiliki potensi yang tinggi untuk berkembang. Faktor yang dapat mendukung perkembangan tersebut adalah pemanfaatan teknologi dan peningkatan kualitas Sumber Daya Manusia (SDM) yang dimiliki Indonesia.

"Ekonomi digital adalah sumber daya baru yang dimiliki Indonesia. Kalau kita terus mengandalkan SDM, kita akan tertinggal jauh dan proyeksi ekonomi Indonesia pada 2030 pun tak akan bisa direalisasikan," jelas Bhima. Menurutnya, kini Indonesia harus mengembangkan ekonomi berbasis pengetahuan, yakni pengetahuan seputar Artificial Intellegence (AI), Virtual Reality, dan Big Data Analysis. Hal tersebut dapat semakin mendorong ekonomi digital di Indonesia, terutama dalam revolusi industri 4.0. 


\section{P-ISSN 2716-3652 E-ISSN 2723-1003 \\ DEDIKASI PKM UNPAM}

Vol. 1, No. 3, September 2020, Hal (103-108)

@Prodi Manajemen Fakultas Ekonomi Universitas Pamulang

Keuntungan dari revolusi tersebut adalah meningkatnya kualitas produk, adanya efisiensi biaya operasional, peningkatan penjualan, dan perluasan konsumen. Menurut Bhima, China dan Jerman sudah mulai menerapkan sistem otomatisasi robot di beberapa pabrik mereka. China, bahkan menyediakan kawasan industri Shenzen. Jadi, meskipun memanfaatkan teknologi, kecerdasan, dan kemampuan manusia dalam mengembangkan teknologi tetap dibutuhkan. Hal serupa dapat diterapkan pada banyak startup yang kini tengah tumbuh di Indonesia. Menurut situs startuprankink, Indonesia telah memiliki 1.559 startup dan menduduk peringkat ke-3 dengan jumlah startup terbanyak di dunia.

Untuk menghadapi perubahan yang dibawa industri 4G Indonesia pun sudah bersiap mengantisipasinya. Salah satunya dengan meningkatkan kompetensi Sumber Daya Manusia (SDM) melalui program link and match antara pendidikan dan industri. Kebijakan link and match ini dilaksanakan untuk memastikan agar kompetensi yang dimiliki SDM Indonesia sudah sesuai dengan kebutuhan industri berbasis teknologi digital, seperti halnya revolusi industri $4 \mathrm{G}$

Dari latar prolog diatas dapat dirumuskan masalah yang ada yaitu: Bagaimana peluang masyarakat (warga Cicalengka Kecamatan Pagedangan) dalam kewirausahaan di era industry digital 4G? dan Bagaimana menjalankan menejemen kewirausaha pada era industry digital 4G?. Kegiatan PKM ini bertujuan untuk: Mengetahui bagaimana peluang masyarakat (warga Cicalengka Kecamatan Pagedangan) dalam kewirausahaan di era industry digital 4G, Mengetahui bagaimana menjalankan menejemen kewirausaha pada era industry digital 4.0 di warga Cicalengka Kecamatan Pagedangan, Membangun masyarakat yang berkarakter kuat, mandiri, produktif dan kreatif serta inovatif dalam berwirausaha.

\section{B. METODE PELAKSANAAN}

Sebelumnya tim PKM juga melakukan komunikasi dengan beberapa alumni Survey tempat/lokasi pelaksanaan pengabdian kepada masyarakat yang akan diadakan oleh team PKM sesuai tema PKM yaitu; Metode pendekatan dalam pengandian masyarakat yang dilakukan warga Cicalengka Kecamatan Pagedangan yang beralamat di Jl Pagedangan kp pagedangan RT 001 RW 002 Desa Cicalengka kecamatan Pagedangan Kabupaten Tangerang-Banten dengan menggunakan metode dalam bentuk pelatihan keterampilan dilakukan dengan 1. Ceramah dan tanya jawab tentang menejemen kewirausahaan dilaksanakan pada tanggal 5 September 2020 2. Pelatihan teknis kewirausahaan pada era industry 4.0 dilaksanakan pada tanggal 6 September 2020. 3. Pendampingan dalam berwirausahaan pada era industry 4G dilaksanakan pada tanggal 5 - 6 September 2020yang dilaksanakan sesuai tahapan. Adapun tahapan-tahapan dalam pelaksanaan kegiatannya :

1. Ceramah digunakan untuk menyampaikan pengetahuan secara umum tentang Enterpreneur/ kewirausahaan pada era industry digital 4G kepada seluruh warga Cicalengka Kecamatan Pagedangan.

2. Demontrasi digunakan untuk memberikan keterampilan langsung mengenai Enterpreneur/ kewirausahaan pada era industry digital 4G kepada seluruh warga Cicalengka Kecamatan Pagedangan

3. Tanya jawab digunakan untuk melengkapi hal-hal yang belum terakomodasi oleh kedua metode diatas

4. Game/Pelatihan, dilakukan oleh seluruh peserta pelatihan agar tidak bosan dalam mengikuti pelatihan tersebut.

5. Evaluasi hasil akhir. Dilakukan secara bersama-sama baik oleh Tim Pengabdian Masyarakat, warga Cicalengka Kecamatan Pagedangan. 


\section{HASIL DAN PEMBAHASAN}

Didalam pengabdian yang dilakukan oleh dosen menejemen ini dengan cara menyampaikan materi atau diskusi secara langsung yaitu: materi membagun dan motivasi berwirausaha yang disampaikan oleh Suwanto, S.E., M.M. dalam bentuk ceramah/presentasi kemudian dilanjutkan pada materi ke dua (2) yaitu dengan materi Kewirausahaan UMKM melalui E Comer yang disampaikan oleh Priehadi Dhasa Eka, S.E,. M.M. dengan 3) materi Motivasi dan Etika dalam bisnis/berwirausaha presentasi yang disampaikan oleh Angga Juanda S,Si, M.M. dan 4) materi cara berwirausaha dengan online yang disampaikan oleh Muhammad Gandung, S.E., M.M dan 5). materi Digital Marketing yang disampaikan oleh Prasetyo Kurniawan, S.E., M.M. diseliingi dengan game untuk menghilangkan kejenuhan pada pelatihan ini. Dan game ini juga bertujuan untuk menggali potensi baik yang ada pada sumber daya manusia maupun sumber daya alam yang ada di warga Cicalengka Kecamatan Pagedangan. Pada hari terakhir acara pelatihan dilanjut dengna FGD, tentang masalahmasalah yang dihadapi oleh warga Cicalengka Kecamatan Pagedangan dikaitkan dengan kebutuhan pelatihan untuk menyelesaikan masalah yang ada. Ternyata masalah yang paling banyak memang masalah pada diri pribadi yaitu bagaimana memulai usaha di era 4G dengan menggunakan teknologi yang ada.

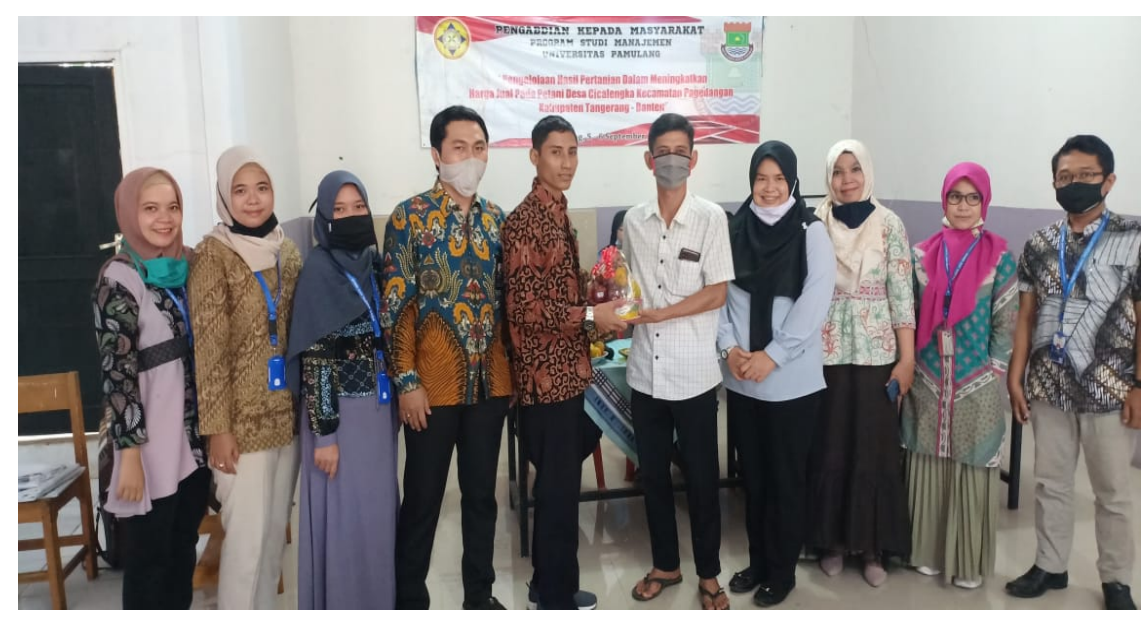

Gambar 1. Pemberian Bingkisan Kepada Warga

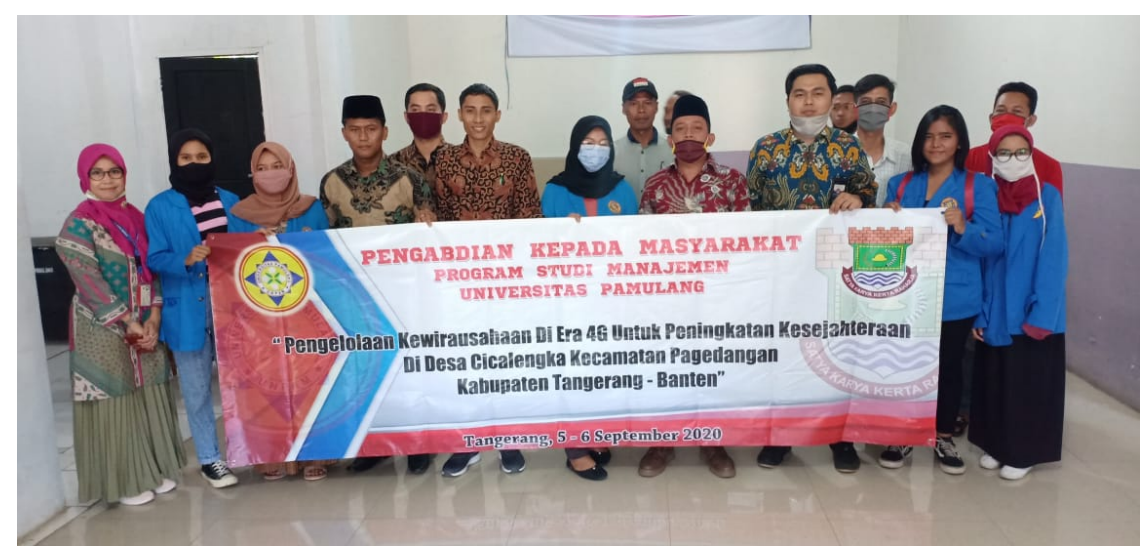

Gambar 2. Foto bersama Kepala Desa dan Warga 


\section{KESIMPULAN DAN SARAN}

\section{Kesimpulan}

1. Setiap masyarakat dalam hal ini warga Cicalengka Kecamatan Pagedangan memiliki peluang yang sama dengan masyarakat yang lainnya dalam menjalankan kewiraussahaan di era industry digital $4 \mathrm{G}$ setelah mendapatka pelatihan dan motivasi dan harus berani untuk memulainya.

2. Menjalankan menejemen kewirausaha pada era industry digital $4 \mathrm{G}$ dapat dilakukan oleh siapa saja, kapan saja tidak mengenal tempat dan waktu dan siapa pelanggannya, terlebih yang menjalankan bisnis tersebut adalah anak-anak muda yang tergolong anak milenial

\section{Saran}

1. Kegiatan Pengabdian Kepada Masyarakat (PKM) yang dilakukan oleh Unpam hendaknya tidak berhenti pada satu kegiatan. Perlu adanya PKM yang berkesinambungan, sehingga masyarakat merasakan dampak dan manfaat dari keberadaan Unpam secara berkelanjutan.

2. Perlu dibuat metode yang tepat dalam melaksanakan kegiatan PKM oleh dosen-dosen Unpam

\section{DAFTAR PUSTAKA}

Baihaqi M. (2019) November 14. Peran E Comer Dalam Pengembangan Umkm (N.I. Nizar, Interviewer)

Bertus Heri. (2013) Mei 23. Langkah-Langkah Dalam Bisnis Online. Unpad. Bandung

Dumilah, R., Sunarto A., Ahyani, Solihin, D., Maulida H. (2020). Pelatihan Pemanfaatan Media Sosial Untuk Promosi Usaha Atau Bisnis Bagi Siswa. Dedikasi Pkm. Vol. 1. No. 1.

Endah Alberthiene. (2011). The Passion Of My Life. Jakarta.

Fahmi Irham. (2011) Manejemen Resiko. Bandung Alfabeta

Gandung, M., \& Suwanto, S. (2020). Analisis Pengaruh Kompensasi Dan Gaya Kepemimpinan Terhadap Kinerja Karyawan Pada Pt. Surya Rasa Loka Jaya Di Jakarta Barat. Jenius (Jurnal Ilmiah Manajemen Sumber Daya Manusia), 3(3), 236-245.

Hasibuan Sp Melayu. (2013). Manajemen Sumber Daya Manusia. Jakarta Pt Bumi Aksara Handoko Tani. (2011) Manejemen Personalia \& Sumber Daya Manusia. Jogjakarta Bpfe Hendro. (2011). Be A Smart And Good Enterpreneur . Jakarta. Media Presindo

Mardiana, S., Supriyatna., W., Zakaria, Dumilah, R., \& Budhiarjo, I. S. (2020). Sosialisasi Dan Penyuluhan Tentang Pentingnya Menabung Bagi Generasi Muda Khususnya Siswa Madrasah Tsanawiyah Mts Mathlaul Anwar Pamulang. DEDIKASI PKM. Vol. 1. No. 2.

Priehadi Dhasa Eka N Suwanto 2020, Audit Sumber Daya Manusia, Desanta Muliavisistama

Solihin, D. (2020), "Faktor-Faktor Yang Mempengaruhi Kinerja Pemasaran Pada PT Prima Ufuk Semesta (Studi Empiris Pada Outlet Rekanan PT. Prima Ufuk Semesta di Wilayah JABODETABEK)", Jurnal Semarak, Vol. 3. No. 1. 
Solihin, D. (2020), "Pengaruh Kepercayaan Pelanggan Dan Promosi Terhadap Keputusan Pembelian Konsumen Pada Online Shop Mikaylaku Dengan Minat Beli Sebagai Variabel Intervening". Jurnal Mandiri. Vol. 4. No. 1.

Solihin, D., dan Wibawanto, E. (2020). "Pengaruh Kualitas Pelayanan, Harga, Dan Promosi Terhadap Keputusan Pelanggan Dalam Memilih Klub Basket Satria Indonesia Tangerang Selatan". Jurnal Pemasaran Kompetitif. Vol. 3. No. 3.

Solihin, D. (2019), Pengaruh Current Ratio dan Debt To Equity Ratio Terhadap Return On Asset (ROA) Pada PT Kalbe Farma, Tbk. KREATIF: Jurnal Ilmiah Prodi Manajemen Universitas Pamulang 7 (1), 115-122.

Suwanto 2020, Manajemen Sumber Daya Manusia, Desanta Muliavisistama

Suwanto 2020, Strategi Pemberdayaan Potensi Pemuda Karang Taruna, Desanta Muliavisistama

Suwanto, S. (2019). Pengaruh Disiplin Kerja Dan Motivasi Kerja Terhadap Kinerja Karyawan Pada Rumah Sakit Umum Tangerang Selatan. Jenius (Jurnal Ilmiah Manajemen Sumber Daya Manusia), 3(1), 16-23.

Suwanto, S. (2019). Pengaruh Disiplin Kerja Dan Motivasi Kerja Terhadap Kinerja Karyawan Pada Rumah Sakit Umum Tangerang Selatan. Jenius (Jurnal Ilmiah Manajemen Sumber Daya Manusia), 3(1), 16-23.

Suwanto, S., Eka, P. D., Agusentoso, R., Juanda, A., \& Kurniawan, P. (2020). Menggali Potensi, Memotivasi Dan Mengarahkan Generasi Muda Menyongsong Dunia Kerja Pada Pkbm Cipta Tunas Karya Cipondoh Kota Tangerang. Jurnal Pengabdian Dharma Laksana, 2(2), 132-136.

Suwanto, S., \& Eka, P. D. (2020). Analysis Of Leadership Style Influence, Job Motivation, And Compensation Towards Teacher Satisfaction On The Foundation Of Al-Hasra Bojongsari. Depok City. International Journal Of Advances In Social And Economics, 2(3).

Suwanto, S. (2019). Pengaruh Gaya Kepemimpinan Dan Lingkungan Kerja Terhadap Kinerja Karyawan Unit Telesales Pada Pt Bfi Finance Indonesia Tbk. Jurnal Ekonomi Efektif, $1(2)$. 